\title{
Vaccine-related Discussions in Online Communities for Parents. A Quantitative Overview
}

\begin{abstract}
Vaccinations are a medical success story. However, many individuals still experience doubts, which challenge vaccine compliance. Online communities for parents are important sources for the discussion about vaccination with similar others. They serve as social support platforms, where parents exchange informational, emotional, and esteem support. Our study provides a structured overview of vaccine-related online discussions of parents. The content of the four most popular German online communities for parents (2012-2019) was obtained with web scraping. Structural topic models were used to characterize the exchanges about vaccination in 98,505 discussion posts. We identified 27 aspects of the vaccination discussions, which were sorted into four general perspectives. The general vaccination debate perspective ( 6 aspects, 24\% of all content) covered societal and public health debates. The specific vaccinations perspective ( 8 aspects, 16\%) addressed vaccinations against specific diseases. Parents discussed various vaccine-related practical issues (7 aspects, 20\%). The relationship and communication perspective (6 aspects, 19\%) collected aspects concerned with community building. The findings highlighted the diversity of vaccine-related online discussions related to all types of social support. Investigating online exchanges can inform public health communicators as well as health professionals which parental support needs should be addressed more comprehensively.
\end{abstract}

Keywords: vaccination; vaccine-related discussions; social network platforms; online communities for parents; enacted social support; topic models; web scraping. 


\section{Diskussionen über das Impfen in Elternforen. Ein quantitativer Überblick}

\section{Zusammenfassung}

Impfungen sind eine medizinische Erfolgsgeschichte. Allerdings sind noch immer viele Personen kritisch gegenüber dem Impfen eingestellt. Elternforen im Internet sind wichtige virtuelle Orte für einen Austausch rund um Impfungen mit anderen Personen, die sich in ähnlichen Situationen befinden. Sie dienen als Plattformen für soziale Unterstützung: Eltern können sich dort gegenseitig mit dem Austausch von Informationen, Emotionen und Wertschätzung unterstützen. Unsere Studie gibt einen systematischen Überblick über Internet-Diskussionen von Eltern zum Thema Impfen. Dazu haben wir die relevanten Inhalte aus den vier meistgenutzten deutschsprachigen Elternforen von 2012 bis 2019 mit Web Scraping gesammelt. Der Austausch zum Thema Impfen in 98,505 Posts wurde mit Structural Topic Models analysiert. So identifizierten wir 27 Aspekte der Impf-Diskussionen, die sich vier übergeordneten Perspektiven zuordnen ließen. Die Perspektive Allgemeine Impf-Debatte (6 Aspekte, insgesamt 24\% des Inhalts) beschäftigte sich mit der gesellschaftlichen Dimension des Impfens und dem Beitrag zum öffentlichen Gesundheitsschutz. Die Perspektive Spezifische Impfungen (8 Aspekte, 16\%) beinhaltete Diskussionen zu Impfungen gegen bestimmte Krankheiten. Es gab einen Austausch zu Praktischen Fragen (7 Aspekte, 19\%). Die Perspektive Beziehungen und Kommunikation (6 Aspekte, 19\%) sammelte Aspekte mit Bezug zu Aufbau und Erhalt einer Internet-Gemeinschaft von Eltern. Die Ergebnisse verdeutlichen die Vielfalt der Diskussionen von Eltern zum Thema Impfen. Die Untersuchung von Impf-Diskussionen in Elternforen kann dazu beitragen, die Bedürfnisse von Eltern nach sozialer Unterstützung zu identifizieren. Daraus lassen sich Hinweise für die öffentliche Gesundheitskommunikation sowie für die Kommunikation zwischen medizinischen Fachkräften und Eltern ableiten.

Schlagwörter: Gesundheitskommunikation; impfbezogene Diskussionen; Soziale Netzwerke; Internetforen für Eltern; soziale Unterstützung; Topic Models; Web scraping. 


\section{Vaccine-related Discussions in Online Communities for Parents. A Quantitative Overview}

Vaccinations are a medical success story. For example, measles vaccination alone saves up to 1.3 billion lives worldwide every year (World Health Organization (WHO), 2019). Early childhood vaccinations are particularly important, because they protect infants and children from potentially life-threatening disease and contribute to herd immunity. The majority of the public is aware of the benefits of vaccines. Yet doubts, uncertainties and concerns about vaccine safety and efficacy continue to be part of private and public vaccine-related discussions and of individuals' decision-making (Fadda et al., 2015; Harmsen et al., 2013; Modanloo et al., 2019; Nan \& Daily, 2015; Rosselli et al., 2016). The advent of the Internet and, in particular, of social networking sites has increased the spread of vaccine-related doubts in the eyes of some public health scholars, who described vaccine-related online communication as a "postmodern Pandora's box" (Kata, 2010; Rosselli et al., 2016). However, research on health-related social media content and use has also shown many beneficial outcomes (Meng et al., 2017; van Ingen et al., 2016). Namely, online discussions and peer communication can fulfil various social support functions (Meng et al., 2017; Oh \& Lee, 2012).

In this article, our aim is to explore the vaccine-related discussions on a specific type of social networking sites - online communities for parents - from a social support perspective. Our research aim is focused on the nature of "enacted social support" (Barrera, 1986, p. 417) that shed light on performed supportive transactions that took place in online communities.

Online communities combine the credibility of interpersonal persuasion with the mass media's large audiences. To engage in online communities potentially results in effects on 
knowledge, attitudes, or behaviours among a large group of people like parents seeking for advice about vaccine-related decision-making (Kim et al., 2020; Teoh, 2019). Parents are an especially relevant population, because they are the main decision-makers for (or against) childhood vaccinations (Dworkin et al., 2013; Harmsen et al., 2013; Limaye \& Salmon, 2017). In Germany, our empirical case, and similarly in many industrialized societies with universal health-care systems, but without mandatory vaccinations, almost every parent has to decide early in a child's life whether, and if so, which vaccines will be applied. In general, being a parent is associated with online health information seeking on behalf of one's children (Byström et al., 2020; Reifegerste \& Bachl, 2019). Today’s parents of younger children are in the demographic groups which are most likely to seek and share online health information (Bachl, 2016; National Cancer Institute, 2017; Link \& Baumann, 2020). Vaccine-related online communication of parents is therefore a relevant research subject.

Online communities provide parents with ample opportunities for health-related exchanges. In particular, they are platforms that enable the enactment of various types of social support for vaccine-related decision-making and coping with uncertainties or emotional distress. However, the performed social support in vaccine-related exchanges in online communities for parents has, to the best of our knowledge, not yet been studied empirically at scale. Previous work mainly investigated vaccine-related content on general social media platforms (e.g., Facebook, Twitter, YouTube) and on dedicated anti-vaccine websites. Scholars focussed more narrowly on discussions about specific vaccines, pro- and anti-vaccine arguments, and information quality (see the subsequent literature review). Such studies contributed to the discourse about the threats of social media to vaccine acceptance, but neglected the wider spectrum of possibly beneficial social support functions of online exchanges. 
To broaden the research scope and in light of the scant empirical knowledge about online communities for parents, we chose to explore the vaccine-related exchanges with a quantitative topic modelling approach. A topic model is able to identify meaningful patterns in large quantities of texts. It "combines an inductive approach with quantitative measurements, making it particularly suitable for exploratory and descriptive analyses" (Maier et al., 2018 p. 94). The extracted topics are then interpreted through a social support lens. In addition, the explorative overview can be a starting point for academic and applied health communication perspectives on vaccine-related online communication of parents (Betsch et al., 2019; Harmsen et al., 2013; Ratzan et al., 2019). Our research question is:

Which aspects characterize the vaccine-related discussions in online communities for parents with regard to social support transactions?

\section{Social Support in Online Communities for Parents}

Online communities for parents seem ideally suited to provide relevant communication opportunities for their users. They allow for peer-to-peer-communication between people with shared interests and experiences - such as being parents and caring for the health of their children (Ginossar, 2008; Tanis, 2012). To participate in online communities is a convenient, fast, need-oriented and self-determined way to exchange health-related information and opinions, interact socially, and gain feedback (Cline \& Haynes, 2001). These characteristics make online communities predestined to offer access to first-hand social support from peers who share the experiences and challenges of parenthood (Coulson, 2005; Ginossar, 2008; Meng et al., 2017). Social support is generally understood as positive social resource consisting of a range of assistances that people can provide to one another (Tanis, 2008). In particular, enacted social support focuses on behavioural observations of socially supportive communication (Barrera, 1986; Coulson, 2005). Social support can contribute to well-being, 
and helps to cope with uncertainty and anxiety. It is also associated with health outcomes like empowerment for decision-making (Jiang \& Street, 2017). Social support is likely to be important in the context of vaccine-related decision-making and attitude formation, because open questions and doubts about vaccine safety and efficacy might produce feelings of uncertainty (Brashers, 2001) and increase parents' needs to gain social support by information seeking and sharing experiences and feelings.

\section{Types of Social Support in Online Communities}

Social support can be differentiated into three more specific types found to be prevalent in online contexts: informational support, emotional support, and esteem support (Coulson, 2005; Eysenbach et al., 2004; Lee \& Hawkins, 2010; Love et al., 2012; Oh \& Lee, 2012). Only informational support has yet been examined concerning enacted social support in vaccine-related online discussions. However, we can draw on research on social support through online communities and social networking sites in general to form some expectations about enacted vaccine-related social support (for an overview Ginossar, 2008; Meng et al., 2017; Mohd Roffeei et al., 2015). Some studies reported that emotional support was the most frequent type of social support (Love et al., 2012; Malik \& Coulson, 2011), whereas other studies highlight the relevance of informational support (Coursaris \& Liu, 2009; Gray, 2013; Keating, 2013; Link et al., 2016).

\section{Informational Support}

Informational support refers to the sharing of information, which is understood as a valuable resource for health promotion and prevention efforts like increasing vaccine compliance (Kreps, 2008). It is important to note that informational support goes beyond the transmitting of medical facts, which is included in the subdimension teaching (Cutrona \& Suhr, 1992). Other subdimensions are sharing experiences, opinions, and ideas with others or 
to reassess a situation and to refer others to a source of help (Coulson, 2005; Cutrona \& Suhr, 1992). With the absence of physical proximity among most members of an online community, a fourth type of social support, instrumental or tangible support (Holt-Lunstad \& Uchino, 2015), is considered to be a specific type of informational support focused on practical advice. Thus, to forward information, to offer help or assistance in a specific situation, and to offer information and share information helping to plan concrete actions (Coulson, 2005; Tanis, 2008; van Ingen et al., 2016) is another subtype of enacted informational support.

Most of prior work on vaccine-related online communication is directly or indirectly related to informational support. Studies about the effects of participating in online communities and social networking sites indicate that peer-to-peer-communication and shared informational support may, depending on its content, increase or decrease knowledge about and attitudes toward vaccines. Knowledge gain and attitude formation, in turn, have the ability to influence vaccine decisions (Mohanty et al., 2018; Nan \& Daily, 2015; Rosselli et al., 2016; Teoh, 2019). There is some research on vaccine-related content on general social media platforms like Facebook, Twitter or YouTube, which can inform our expectations with regard to informational support (Ekram et al., 2019; Keelan et al., 2007, 2010; Nicholson \& Leask, 2012). The studies highlight the importance of exchange of vaccine-related recommendations and experiences among peers (Mohanty et al., 2018; Nan \& Daily, 2015; Rosselli et al., 2016; Teoh, 2019). In addition, studies distinguished between pro- and antivaccine messages and described their characteristics. For example, Teoh (2019) showed, that pro-vaccine messages were more likely to be fact-based and highlighted the benefits of vaccinations. Anti-vaccine messages were more emotional, reported personal stories about harms and emphasized negative side effects of vaccines. Vaccine efficacy was rarely mentioned, whereas conspiracy theories related to health professionals, the government, and 
pharmaceutical industries were discussed. As the practical accessibility and affordability of vaccines are known factors influencing decision-making and compliance with vaccines (Thomson et al., 2016), it can also be assumed that planning doctor's visits for vaccination and helping each other with issues like vaccine access and affordability are relevant issues of online exchanges among parents.

The informational support in vaccine-related online discussions can be problematic, because facts, experiences, advice, and opinions are not always reliable. In particular, studies on user-generated content, such as exchanges via Facebook, Twitter or YouTube, showed high prevalence of conflicting, misleading or false information (Kata, 2010; Keelan et al., 2010; Rosselli et al., 2016). In general, the exchange is difficult to control. Consequently, misleading and false information, for example about the risk and severity of side effects, might be spread (Kata, 2010; Keelan et al., 2010; Teoh, 2019).

\section{Emotional Support}

Emotional support refers to empathetic expressions, expression of care, empathy, sympathy, encouragement and support to cope with emotional stress, doubts and uncertainty (Eichhorn, 2008; Oh \& Lee, 2012). It is a relevant contributor to online communities' ability to improve their users' mood (Chung, 2014). Hence, online communities are considered a major source of emotional support for various health-related challenges. For vaccination, the access to other parents might be perceived as emotionally supportive and used to demand for or provide emotional support, because similar others with comparable experiences are often especially capable of showing empathic understanding and giving appropriate advice to cope with the emotional stress (van Ingen et al., 2016).

\section{Esteem Support}

The third type of social support is esteem support. It describes communicative actions like validation and agreement with individuals' perspective on a situation (Cutrona \&Suhr, 
1992). Esteem support is relevant to increase self-worth and self-efficacy among community members. Studies showed that the exchange in online communities is able to increase members' sense of empowerment, which is associated, for example, with more active communication with health professionals and higher involvement in medical decision-making (Oh \& Lee, 2012). Having discussed vaccine-related issues in an online community might strengthen parents' self-efficacy and provide reassurance for attitude formation and decisionmaking. In addition, to participate in online communities can also create a sense of community for their members (Oh et al., 2014). Some members, who actively provide social support to others, might be seen as role models by others. Acknowledgements of this position can first increase the self-esteem of the support givers and, in turn, also the confidence of those who follow their advice (Thoits, 2011).

Overall, the literature on social support in online communities (Meng et al., 2017) suggests that peer communication with similar others in comparable situations serves as source and satisfies needs for informational, emotional, and esteem social support. It can be expected that sharing different types of social support is a relevant part of the exchanges about vaccines in online communities for parents. Prior work on vaccine-related online content mainly provided directions on characteristics of informational support, which might be shared on social networking sites. However, given the more general literature, it seems sensible to also include the other social support types in a broader analysis of the vaccinerelated discussions. In the subsequent empirical study, we describe the various aspects of the vaccine-related discussions in online communities for parents through the lens of the three social support types. 


\section{Methods}

\section{Study Design}

We conducted an observational study of vaccine-related posts in four German online communities for parents. We took a quantitative, exploratory topic modelling approach to provide an overview about an under-researched area with an analysis of large quantities of textual content. Our empirical approach is documented in more detail in the online supplementary materials: [link removed for blind review; submitted as supplementary materials].

\section{Selection of Online Communities}

The four German online communities for parents with the greatest reach according to the audience research provider IVW were selected for inclusion in the study: Urbia (https://www.urbia.de/forum; 4,5 million median monthly visits and 9,2 million median monthly page impressions [PIs] between June 2017 and June 2019), Rund ums Baby (https://www.rund-ums-baby.de/community_foren.htm; 4,2 million visits; 11,4 million PIs), Netmoms (https://pwa.netmoms.de/boards; 4,0 million visits; 5,7 million PIs), and Babycenter (https://www.babycenter.de/community; 2,6 million visits; 13,5 million PIs) (IVW, 2019).

\section{Data Collection, Selection, and Preparation}

We collected the publicly available vaccine-related posts with custom web scraping scripts. The initial data collection took place in July 2019. Each platform's search function was used to search for the very general term "impf" (roughly equivalent to the search term "vaccin" in English texts). The links to all discussion threads were collected from the search results. We initially aimed at high recall at the expense of also collecting false positives. That is, we tried to retrieve all vaccine-related posts at the risk of also collecting posts which were irrelevant to the issue. The irrelevant posts could be filtered out more conveniently once they were 
made available in a structured database. The relevant content from the discussion threads was retrieved in a structured format and saved to a database. For this article, the relevant content included the text of the posts, the publishing date, and the platform. Overall, 8,406 discussion threads with $1,164,303$ posts were retrieved. Note that only one single post in a whole thread had to mention the search term for all posts to be collected, so many posts were about topics unrelated to vaccination. We therefore first narrowed down the material to posts which either

a) included the term "impf", or

b) followed directly to a post with the term "impf", or

c) were published in a thread whose initial post included the term "impf" $(134,028$ eligible posts).

Second, we excluded posts about animal vaccination based on a keyword list $(132,104$ eligible posts). Third, we included only posts published since 2012 (126,781 eligible posts) because that was the earliest time for which posts were available in all communities. Finally, we removed all posts with less than 20 words, because very short texts do not contain enough information for the quantitative text analysis (98,588 eligible posts). Table 4.1 in the online supplementary materials summarizes the number of eligible posts after each data selection step for each platform.

The texts of the single posts were prepared for the analysis following the recommendations of the methodological literature on topic modelling (Maier et al., 2018; Schofield \& Mimno, 2016): All words were set to lower-case. German stop words (frequent words which do not differentiate between texts), punctuation, and links were removed. Relevant bi- and tri-grams (meaningful combinations of two or three words) were included in addition to single terms. Terms which occurred in less than $0.5 \%$ or in more than $99 \%$ of all posts were pruned from the dataset. The final dataset for the analysis consisted of 98,505 posts and 1,016 terms. 


\section{Data Analysis}

Structural topic models were used to explore and structure the content of the vaccine-related discussions. Topic models use a bag-of-words approach to infer patterns - i.e., topics - from the co-occurrence of words and other terms in the posts. We estimated the topic models with the recommended prior settings and initialization method (Roberts et al., 2014, 2019). A central modelling decision concerns the number of topics. Models with fewer topics identify more general themes at the expense of omitting potentially interesting aspects. Models with more topics capture more details at the expense of overlap between topics. We selected the model, which was most adequate for our research aims, by multistep model comparison. First, seven models with 10 to 70 topics in steps of 10 were compared by four quantitative fit measures: held-out likelihood, multinomial dispersion of the residuals, semantic coherence, and exclusivity. ${ }^{1}$ Based on the fit measures, the range from 30 to 50 topics was judged as most promising. Two additional models with 35 and 45 topics were estimated. A first qualitative assessment of the five models narrowed down the range to 30 to 40 topics. All 11 models with between 30 and 40 topics were estimated and inspected by two researchers using qualitative content analysis (Mayring, 2014). We used the 10 most typical terms (see Table 1) as well as the 20 most typical posts to identify the substantial meanings of the topics. To ensure mutual agreement, findings were discussed among the research team at different points of the analysis process. The model with 35 topics was judged the most appropriate compromise between general topics and informative details, and it also showed good relative model fit. It is common that not all topics are useful with reference to the research aims (Maier et al., 2018). We decided to exclude eight topics from the result presentation. Two topics had no meaningful interpretation and six topics were not related to

${ }^{1}$ The fit measures for all models are reported in the supplementary materials. 
vaccination. The remaining 27 topics can be considered as specific aspects of the vaccinerelated discussions. Based on a cluster analysis of co-occurrences in the posts, the 27 topics were grouped into four more general perspectives on the vaccination issue. The detailed procedure and results of the cluster analysis are also documented in the supplementary materials.

\section{Results}

We identified four perspectives of the vaccine-related online discussions, which each covered between six and eight specific aspects. Figure 1 summarizes the 27 aspects, their prevalence, and their assignment to the four broader perspectives. Table 1 presents the English translations of the most typical terms for each aspect. More detailed descriptions of the aspects as well as the original typical terms and example posts are documented in the supplementary materials.

\section{Description of the four perspectives of the vaccine-related online discussion}

[Figure 1 and Table 1 here]

General vaccination debate. The first perspective was concerned with the general vaccination debate. The perspective showed the vaccination issue mainly as a societal, political and public health debate between supporters and critics. The perspective included six aspects, which together made up $23.6 \%$ of all content. ${ }^{2}$ The aspect responsibility and threats $(3.3 \%)$ addressed parents' responsibility for vaccination decisions and for the health of their own children and other children. The threats of vaccine hesitancy for public health on

\footnotetext{
${ }^{2}$ The shares for the general perspectives are the sums of the shares of the aspects. All perspectives or aspects, respectively, sum up to less than $100 \%$ because of the shares of the eight omitted topics (see Section 3.4).
} 
the one hand and adverse effects of vaccines for individuals on the other hand were weighted against each other. The related aspect of compulsory vaccination $(3.2 \%)$ put the focus on (early) childhood vaccination in the context of childcare facilities and schools, with the threat posed by unvaccinated children to larger groups as a central theme. Opinions on political regulations of vaccinations were exchanged. A more specific aspect covered ingredients of vaccines $(2.8 \%)$. Critics warned against the potential harms of adjuvants (especially aluminium). Proponents argued against the relevance of such risks. The more general processes, through which vaccines achieve immunization, were also part of this aspect. Further, the general vaccination debate perspective included two meta-debates. The first was concerned with available information on vaccines. It highlighted the aspect of the scientific evidence base $(5.1 \%)$, with discussions on the quality of research and the impartiality of studies with regard to commercial interests, and the availability and quality of information sources $(2.8 \%)$ for the general public. The second meta-debate addressed the aspect of discussion tone $(6.3 \%)$ in vaccine-related exchanges among parents. The debate was perceived and described as heated, sometimes rude, and unwelcoming. A foundational question was whether the users should accept dissenting opinions or whether letting others share their opinion unopposed would create false impressions of the state of the discussion.

Specific vaccinations. The second perspective focused on specific vaccinations and highlighted the process of decision-making. The perspective included eight aspects, which together accounted for $15.8 \%$ of all content. Most aspects placed special emphasis on characteristics of the respective vaccination and the relevant diseases. Three specific aspects focused mainly, but not exclusively, on (early) childhood vaccinations. The aspect about measles and mumps (2.1\%) focused on combined vaccines against both diseases. Posts with this aspect covered the danger of the childhood diseases, dealt with the effectiveness of the vaccines, and the need to be vaccinated in different subpopulations. The aspect about 
meningococcal vaccines (1.2\%) primarily discussed vaccines against the different strains and the recommendations of the Standing Committee on Vaccination. Posts about chickenpox vaccination $(2.4 \%)$ placed an emphasis on the pathogens of chickenpox and shingles. The courses of both diseases and their interrelation were discussed. One recurring theme were doubts about the harmfulness of the diseases and consequent questions about the necessity to vaccinate in some subpopulations. The other three specific aspects of this perspective were primarily about vaccines for adults and older children. Discussions about tick-borne encephalitis (TBE, 1.5\%) covered the regional and lifestyle-related risks of tick bites and a resulting TBE infection. Many posts described personal experiences with tick bites and individual justifications and rationale underlying vaccination decisions. Influenza (3.2\%) and vaccines against its pathogens was one of the more frequently discussed specific aspects. It collected opinions about, experiences with, and assessments of the effectiveness of influenza vaccines. Doubts about its necessity were prevalent. Exchanges about the differentiation of the common cold from influenza were also common. Booster doses $(1.1 \%)$ against tetanus, pertussis, polio, diphtheria, and hepatitis B were mainly discussed for older children and adults. Users reported their booster vaccinations and exchanged information about recommended and necessary vaccination intervals. Booster doses were often brought up together with the immunity during pregnancy aspect (1.7\%). It dealt with vaccinal immune protection during pregnancy, particularly regarding the immunity to rubella and the slapped cheek syndrome. The posts discussed when immunity should be tested, whether a booster vaccination makes sense during pregnancy, and which risks exist in the absence of immunity. The aspect vaccination decision (2.5\%) consisted of statements on the decision for or against specific vaccinations and the reasons for the decision. The posts were often short answers to general questions about other users' vaccination decisions. 
Practical issues. The third perspective considered practical issues, particularly of childhood vaccinations. It consisted of seven aspects, which in total accounted for $20.1 \%$ of all content. Several aspects covered the timing of vaccinations. The vaccination timetable aspect (4.2\%) described which early childhood vaccines were applied at which age. The vaccination sequence aspect (1.6\%) similarly documented the sequence of early childhood vaccines. Appointments (2.5\%) for vaccinations were another related aspect. One recurring theme was the postponement of vaccinations because of a cold or other illness. More general procedural issues $(3.2 \%)$ were collected in a broader aspect. The posts described various issues which have to be organized when getting a vaccination. An emphasis was on additional vaccinations beyond the recommendations of the Standing Committee on Vaccination. There were exchanges about their side effects, how to obtain the vaccines, and whether health insurance providers would cover the costs. Three aspects were related to the process of being vaccinated at the doctor's and the (immediate) consequences. Experience reports $(2.8 \%)$ included the sequence and timing of vaccinations during the course of the doctor's appointment. In addition, vaccine administration routes, experiences and ways to deal with side effects, reactions of older siblings, and information about organizational and financial questions were exchanged. The tolerability aspect (3.3\%) contained reports that the children tolerated the vaccines well and no (major) side effects occurred. Posts about fever and other vaccination reactions $(2.5 \%)$ described experiences with adverse reactions and offered advice on how to deal with them.

Relationship and communication. The relationship and communication perspective included six aspects, which together made up $18.9 \%$ of the discussions. Three aspects characterized general communication patterns in the vaccine-related exchanges. Requests $(2.3 \%)$ collected the various ways in which users asked the community for social support, including requests of experience reports, opinions, reassurance or compassion. 
Acknowledgements (4.1\%) included signs of gratitude and other reactions to input from others. Users also summarized their conclusions from the discussion and evaluated the contributions' content and tone. The medical advice aspect (4.6\%) included references to advice from doctors and other health professionals and suggestions to ask for professional advice. Three aspects revolved around dealing with unpleasant experiences. Users shared their more general bad experiences $(2.4 \%)$ or provided comfort to those who reported them. A more specific aspect was to describe the immediate reactions $(2.9 \%)$ of small children and babies to the vaccination process and in particular to the injection, which often involved pain and crying. Recommendations were given with regard to pain management and general soothing activities. The aspects were supplemented by recovery wishes $(2.6 \%)$, which expressed empathy and emotional support to those who suffered from bad experiences, unpleasant reactions to the vaccination, or general illness.

\section{The Lens of Social Support on the Four Perspectives}

The descriptions of the aspects and broader perspectives of vaccine-related online discussions will be interpreted more detailed by referring to the three types of enacted social support (see Table 2 for a summary).

[Table 2 here]

\section{Informational Support}

Across all perspectives, the exchange of informational support was prevalent (see Table 2). The subtype teaching of information was found regarding the exchange of knowledge, arguments and opinions pro and against vaccinations. Corresponding requests for and provisions of information pro and against vaccinations characterized those posts related to the general vaccination debate. Teaching and sharing own experiences were also relevant regarding the specific vaccination perspective. As users described the decision-making process as challenging, an exchange of opinions, medical facts and experiences with other 
parents was sought to cope with uncertainties, concerns, and doubts. The aspects put an emphasis on the exchange of information and experiences.

The general vaccination debate also included enacted informational support by referring individuals to information materials about vaccinations and by joint assessment of information and information materials. Both referred to the meta-debate about the availability and quality of evidence-based information. The community members were aware of and sensitive for the relevance of information, but they also described that it was challenging to select trustworthy sources and obtain reliable information. Related to the online context, the users also seemed to be aware that sharing information goes beyond a simple transmission of facts, but might be subject to inherent biases. Referrals to medical experts as another subtype of informational support was found in the perspective relationship and communication.

The informational support subtype of practical advice exchanges in online-communities was prevalent in the perspective of practical issues. Questions of access to vaccinations and affordability of vaccines was found related to organizing a vaccination, coordination with health insurance providers or with taking care of a child during and after a vaccination. The searched and offered support served the preparation and coping of parents. Practical advice considered in the relationship and communication perspective referred to soothing activities during the vaccination.

\section{Emotional Support}

Enacted emotional support was found in three of the four perspectives (see Table 2). Only in the course of the decision-making process, to which the perspective of specific vaccinations mainly referred, emotional support was less prevalent. The meta-debate about the tone of the discussions associated with the perspective general vaccine debate seems especially relevant with regard to emotional support. Appeals for reasonable manners and 
respect for the feelings of others, regardless of their substantial positions, were a recurrent theme related to relationships in online communities.

With regard to practical issues, to provide emotional support was particularly relevant in the context of the emotionally challenging situations during or after a vaccination. The postings could be read as expressions of care as well as sympathy and empathy. The same emotional support subtypes applied to reports of emotionally challenging experiences, the expression of recovery wishes and acknowledgement. All characterized aspects were prevalent in communication and relationship perspective.

Furthermore, reading the positive reports in the tolerability aspect may serve as an encouragement and a counterbalance for parents who fear adverse reactions. This was a relevant aspect regarding practical issues.

\section{Esteem Support}

The transaction of esteem support was prevalent in two of four perspectives: the general vaccination debate and specific vaccines perspectives. The socially supportive communication served the function of validation. The polarized debates observed in posts belonging to the general vaccination debate seem suited to contribute to ideological sorting in the pro- and anti-vaccine camps. For the single user, polarized debates and the possibility to identify with other pro- or anti-vaccine parents can provide users assurance of their beliefs. At the public debate level, however, this can be considered as dysfunctional, as it strengthens the formation of camps.

Asking for and reporting vaccination decisions belonging to the specific vaccination perspective was another noticeable feature, which related to validation as a type of the esteem support function of online communities. Parents were able to gather public support for their decisions and to present themselves as good citizens, who contributed their part to the 
immunization effort - or, depending on one's position, as resistant to the pro-vaccine mainstream.

\section{Discussion}

The vaccine-related discussions in German online communities for parents were characterized by high thematic diversity. They reflected social and political debates on vaccination, specific and practical questions about vaccines and exchanges related to individual' decision-making to vaccinate oneself and one's children. Contrary to some concerns about vaccine-related online information and exchanges on social networking sites (Kata, 2010; Rosselli et al., 2016), the discussions in online communities for parents were not dominated by negative reports of individual emotional cases, horror scenarios, or conspiracy theories. However, the general vaccination debate perspective, which touched upon many issues on the societal level, included critical voices about the efficacy and safety as well as side effects of vaccinations. In general, an open exchange of different opinions (for and against vaccinations), experiences, facts and information prevailed.

The broad spectrum of discussed aspects aligned well with the three social support types (Chung et al., 2014; Meng et al., 2017), which were our primary theoretical lens for the interpretation of the enacted social support forms in the posts. Members of the community provided informational support by sharing medical knowledge on diseases and vaccinations (teaching), sharing own experiences, refer other community members to information and medical expertise and provide practical advice. They offered emotional support in the form of expressions of care, sympathy and empathy and encouragement to cope with uncertainties, fears and sorrows and build relationships. Further, the social act of discussing the issues with peers and to validate opinions also served as coping strategy by building a community and providing esteem support. 
All types of social support were explicitly requested and provided with regard to vaccine-related decision-making. Informational support was the most common support type and occurred frequently in all four perspectives. Teaching and sharing of experiences as subtypes of informational support were found in exchanges about the prevalence and severity of a disease as well as the composition, effectiveness, and safety of specific vaccines. Furthermore, reports about the experiences with side effects and tolerability, as described by other users, were suited to complement medical arguments and can affect decision-making. Particularly, the users' informational needs became apparent in several respects. The online discussions were used to ask for information on a variety of issues, ranging from specialized knowledge on specific vaccines to political arguments and opinionated comments. The communities themselves served as a source of information, with all the caveats which apply to user-generated online (health) content. In a meta-debate, the discussions also turned to the questions of how to find, select, and act upon adequate sources and information, addressing the social support-subtype of referral to information and expertise. Users made explicitly clear that they were aware of conflicting information and of varying quality of information. The need to be informed was acknowledged. However, it was perceived as difficult to evaluate the quality and credibility of vaccine-related information and sources. This problem is a at the centre of debates about media and health literacy and highlight the relevance to empower individuals as precondition of informed vaccine decision-making (Meppelink et al., 2019; Norman \& Skinner, 2006). The exchange of practical advice as subtype of informational support, such as which additional vaccinations are covered by a health insurance and where the vaccines can be retrieved, referred to accessibility as a factor of vaccine-related decision-making (Thomson et al., 2016). In comparison to accessibility, the affordability of vaccines was not among the relevant issues of online exchanges among parents. 
Emotional support included encouraging fearful parents and consoling those who reported adverse reactions to prior vaccinations. Based on the current state of research, it can also be assumed for online discussion about vaccinations that expressions of care, sympathy and empathy as well as understanding and encouragement among parents improve their mood (Chung, 2014) and support their coping with uncertainties and doubts about vaccines, their safety and side effects (Oh \& Lee, 2012; van Ingen et al., 2016).

Esteem support may have been created by the reports of decisions by (many) other individuals. They can serve as validation and heuristic cues for the perception of the public opinion about vaccination. Perceived public opinion, understood as social norm, can be a relevant influence on decision-making, in particular in the group of young parents (Betsch et al., 2012; Kim et al., 2020). Following the social norm on vaccine acceptance may increase self-esteem with regard to the identity as a parent who does the right thing in the view of the majority of parents.

Our findings can be used as a basis for improving both public health announcements and campaigns on vaccination and vaccine-related communication between health professionals and patients. It is argued that providing social support is a major task of health professionals and being aware of supportive needs is of high relevance to institutions like the Robert-Koch-Institut, the WHO or the Bundeszentrale für gesundheitliche Aufklärung (BZgA). They can use this knowledge to design health campaigns and information materials. The explorative description of the aspects, which were discussed in online communities for parents, provides indicators of the supportive needs of parents. Parents are willing to learn more about or need a basic understanding of disease, question the efficacy and safety of vaccinations and fear side effects (Limaye \& Salmon, 2017). Further, they have practical questions related to vaccinations and vaccine-related services. Health professionals can adjust their interpersonal communication with patients and health communicators can adjust public 
announcements to match these social support needs of parents. Based on our findings, communication strategies and interventions should consider the need for general information about disease, which might have an impact on the rise of general doubts about the need to be vaccinated as well as low perceived risk of disease (Kata, 2010; Keelan et al., 2010). Practical advice for planning appointments can also be addressed in public health announcements. The described need for emotional support puts health professionals in charge of support and demand for a trustful patient-provider relationship as well as patient-centred communication to address the patient's emotional and informational needs. In addition, there was some indication of limited trust in the information and recommendations from health professionals and health organizations. Therefore, it is essential to build trust in patientprovider interactions. The media literacy of health professionals also needs to be considered. Trusted and media literate health professionals can refer their patients to high-quality (online) sources. Health professionals engaging in online discussion can be one additional way to interact with patients. Public health organizations need to invest in trust-building communication strategies to be taken seriously in the online information environment.

Our aim was to provide a general overview of the vaccine-related discussions in four German online communities for parents. With our quantitative, explorative analysis of a large body of discussions, we were able to supplement prior research, which focused more narrowly on pro- and anti-vaccine messages, the valence of the discourse, or specific vaccines. Our approach can be used to identify supportive needs, but also monitor public attitudes and opinions on vaccination and offer guidance on how to design (communicative) interventions to achieve higher compliance with vaccinations. However, our approach came with some limitations, which need to be considered when putting the results into context. Our analysis focused on general patterns, but was not suitable for depicting discourses in detail. We therefore refrained from judgements about the consistency or even quality of specific 
lines of arguments, regardless of their position towards vaccination. Similarly, it was not our intention to quantify the relative prevalence of pro- and anti-vaccine messages. We can only state that both viewpoints were represented in various aspects of the discussion. The selection of four specific online communities for parents warranted some caution with regard to the generalization of the findings. Parents are arguably an important target group for vaccinerelated communication and the selected communities are prominent online spaces for their discussions. We believe that the general discussion patterns should also hold for parents who do not use these platforms and for other individuals. This claim is of course speculative until further empirical investigation. Further research should compare different communities, characterize their users, and identify structures and dynamics of discourses. Future work can build on our analysis with more direct and detailed measures of the social support types exchanged in online communities, instead of using social support only as a lens and framework for interpretation. Such future work may focus on the content of the online discussions among parents, but should additionally survey the community members about their supportive needs and triggers to turn online and discuss their feelings, thoughts and decisions with other parents. Moreover, more research on the effects of online communication on individuals' perceptions of vaccines, decision-making, and compliance with vaccines is needed. Further, for analysing online enacted social support, ethical considerations should be discussed. We did not ask the community providers or members for informed consent as we only considered online communities who are publicly accessible. Between 2.6 to 4.5 million visits per month demonstrated, in our view, the public nature of the communities. Further, the members were mostly masked by pseudonyms and we were only interested in the content of the postings.

In conclusion, our study highlights the importance and diversity of online communication of parents about vaccines and vaccine-related decision-making. The results 
showed all forms of enacted social support and indicated that the online exchanges have the potential to fulfil a variety of social support functions. The identified aspects ranged from debates about vaccination as a public health issue to individual decision-making, asking for and providing medical information, sharing experiences, emotional support and asking and answering practical questions about vaccination. As it can be assumed that online social support exchanged among similar others has far reaching consequences for individuals' and public health, further research is needed to describe the discourses and consider its influencing factors and effects. 


\section{References}

Bachl, M. (2016). Online health information seeking in Europe: Do digital divides persist? Studies in Communication and Media, 5(4), 427-453. https://doi.org/10.5771/2192$\underline{4007-1016-4-427}$

Barrera, M. (1986). Distinctions between social support concepts, measures, and models. American Journal of Community Psychology, 14(4), 413-445. https://doi.org/10.1007/BF00922627

Betsch, C., Brewer, N. T., Brocard, P., Davies, P., Gaissmaier, W., Haase, N., Leask, J., Renkewitz, F., Renner, B., Reyna, V. F., Rossmann, C., Sachse, K., Schachinger, A., Siegrist, M., \& Stryk, M. (2012). Opportunities and challenges of Web 2.0 for vaccination decisions. Vaccine, 30(25), 3727-3733. https://doi.org/10.1016/j.vaccine.2012.02.025

Betsch, C., Schmid, P., Korn, L., Steinmeyer, L., Heinemeier, D., Eitze, S., Küpke, N. K., \& Böhm, R. (2019). Impfverhalten psychologisch erklären, messen und verändern [Psychological antecedents of vaccination: definitions, measurement, and interventions]. Bundesgesundheitsblatt - Gesundheitsforschung - Gesundheitsschutz, 62(4), 400-409. https://doi.org/10.1007/s00103-019-02900-6

Brashers, D. E. (2001). Communication and uncertainty management. Journal of Communication, 51(3), 477-497. https://doi.org/10.1111/j.1460-2466.2001.tb02892.x

Byström, E., Lindstrand, A., Bergström, J., Riesbeck, K., \& Roth, A. (2020). Confidence in the National Immunization Program among parents in Sweden 2016 - A crosssectional survey. Vaccine, 38(22), 3909-3917. https://doi.org/10.1016/j.vaccine.2020.01.078

Chung, J. E. (2014). Social networking in online support groups for health: How online social networking benefits patients. Journal of Health Communication, 19(6), 639-659. 
https://doi.org/10.1080/10810730.2012.757396

Cline, R. J. W., \& Haynes, K. M. (2001). Consumer health information seeking on the Internet: The state of the art. Health Education Research, 16(6), 671-692. https://doi.org/10.1093/her/16.6.671

Coulson, N. S. (2005). Receiving social support online: An analysis of a computer-mediated support group for individuals living with irritable bowel syndrome. Cyber Psychology \& Behavior, 8(6), 580-584. https://doi.org/10.1089/cpb.2005.8.580

Coursaris, C. K., \& Liu, M. (2009). An analysis of social support exchanges in online HIV/AIDS self-help groups. Computers in Human Behavior, 25(4), 911-918. https://doi.org/10.1016/j.chb.2009.03.006

Cutrona, C. E., \& Suhr, J. A. (1992). Controllability of Stressful Events and Satisfaction With Spouse Support Behaviors. Communication Research, 19(2), 154-174. https://doi.org/10.1177/009365092019002002

Dworkin, J., Connell, J., \& Doty, J. (2013). A literature review of parents' online behavior. Cyberpsychology: Journal of Psychosocial Research on Cyberspace, 7(2). https://doi.org/10.5817/CP2013-2-2

Eichhorn, K. C. (2008). Soliciting and providing social support over the Internet: An investigation of online eating disorder support groups. Journal of Computer-Mediated Communication, 14(1), 67-78. https://doi.org/10.1111/j.1083-6101.2008.01431.x

Ekram, S., Debiec, K. E., Pumper, M. A., \& Moreno, M. A. (2019). Content and commentary: HPV vaccine and YouTube. Journal of Pediatric and Adolescent Gynecology, 32(2), 153-157. https://doi.org/10.1016/j.jpag.2018.11.001

Eysenbach, G., Powell, J., Englesakis, M., Rizo, C., \& Stern, A. (2004). Health related virtual communities and electronic support groups: Systematic review of the effects of online peer to peer interactions. $B M J, 328(7449), 1166$. 
https://doi.org/10.1136/bmj.328.7449.1166

Fadda, M., Allam, A., \& Schulz, P. J. (2015). Arguments and sources on Italian online forums on childhood vaccinations: Results of a content analysis. Vaccine, 33(51), 7152-7159. https://doi.org/10.1016/j.vaccine.2015.11.007

Ginossar, T. (2008). Online participation: A content analysis of differences in utilization of two online cancer communities by men and women, patients and family members. Health Communication, 23(1), 1-12. https://doi.org/10.1080/10410230701697100

Gray, J. (2013). Feeding on the Web: Online social support in the breastfeeding context. Communication Research Reports, 30(1), 1-11. https://doi.org/10.1080/08824096.2012.746219

Harmsen, I. A., Mollema, L., Ruiter, R. A., Paulussen, T. G., de Melker, H. E., \& Kok, G. (2013). Why parents refuse childhood vaccination: A qualitative study using online focus groups. BMC Public Health, 13(1), 1183. https://doi.org/10.1186/1471-2458$13-1183$

Holt-Lunstad, J., \& Uchino, B. N. (2015). Social support and health. In K. Glanz, B. K. Rimer, \& K. V. Viswanath (Eds.), Health behaviors: Theory, research, and practice (pp. 183-204). New Jersey, US: Wiley.

Informationsgemeinschaft zur Feststellung der Verbreitung von Werbeträgern (IVW). (2019). Online-Nutzungsdaten [Online audience data]. Retrieved from: http://ausweisung.ivw-online.de/

Jiang, S., \& Street, R. L. (2017). Pathway linking internet health information seeking to better health: A moderated mediation study. Health Communication, 32(8), 1024-1031. https://doi.org/10.1080/10410236.2016.1196514

Kata, A. (2010). A postmodern Pandora's box: Anti-vaccination misinformation on the Internet. Vaccine, 28(7), 1709-1716. https://doi.org/10.1016/j.vaccine.2009.12.022 
Keating, D. M. (2013). Spirituality and support: A descriptive analysis of online social support for depression. Journal of Religion and Health, 52(3), 1014-1028. https://doi.org/10.1007/s10943-012-9577-x

Keelan, J., Pavri, V., Balakrishnan, R., \& Wilson, K. (2010). An analysis of the Human Papilloma Virus vaccine debate on MySpace blogs. Vaccine, 28(6), 1535-1540. https://doi.org/10.1016/j.vaccine.2009.11.060

Keelan, J., Pavri-Garcia, V., Tomlinson, G., \& Wilson, K. (2007). YouTube as a source of information on immunization: A content analysis. JAMA, 298(21), 2481. https://doi.org/10.1001/jama.298.21.2482

Kim, H., Han, J. Y., \& Seo, Y. (2020). Effects of Facebook comments on attitude toward vaccines: The roles of perceived distributions of public opinion and perceived vaccine efficacy. Journal of Health Communication, 25(2), 159-169.

https://doi.org/10.1080/10810730.2020.1723039

Kreps, G. L. (2008). Strategic use of communication to market cancer prevention and control to vulnerable populations. Health Marketing Quarterly, 25(1-2), 204-216. https://doi.org/10.1080/07359680802126327

Lee, S. Y., \& Hawkins, R. (2010). Why do patients seek an alternative channel? The effects of unmet needs on patients' health-related Internet use. Journal of Health Communication, 15(2), 152-166. https://doi.org/10.1080/10810730903528033

Limaye, R., \& Salmon, D. (2017). Increasing demand for vaccines: The role of communication. Journal of Communication in Healthcare, 10(1), 6-7. https://doi.org/10.1080/17538068.2017.1299980

Link, E., \& Baumann, E. (2020). Nutzung von Gesundheitsinformationen im Internet: personenbezogene und motivationale Einflussfaktoren [Use of health information on the internet: personal and motivational influencing factors]. Bundesgesundheitsblatt - 
Gesundheitsforschung - Gesundheitsschutz, 63, 681-689. doi:10.1007/s00103-02003144-5

Link, E., Baumann, E., \& Früh, H. (2016). Online discourses about pregnancy: Privacy as a 'price' for supportive communication? Journal of Health and Communication, n.d.(8), 54-64.

Love, B., Crook, B., Thompson, C. M., Zaitchik, S., Knapp, J., LeFebvre, L., Jones, B., Donovan-Kicken, E., Eargle, E., \& Rechis, R. (2012). Exploring psychosocial support online: A content analysis of messages in an adolescent and young adult cancer community. Cyberpsychology, Behavior, and Social Networking, 15(10), 555-559. https://doi.org/10.1089/cyber.2012.0138

Maier, D., Waldherr, A., Miltner, P., Wiedemann, G., Niekler, A., Keinert, A., Pfetsch, B., Heyer, G., Reber, U., Häussler, T., Schmid-Petri, H., \& Adam, S. (2018). Applying LDA topic modeling in communication research: Toward a valid and reliable methodology. Communication Methods and Measures, 12(2-3), 93-118. https://doi.org/10.1080/19312458.2018.1430754

Malik, S., \& Coulson, N. S. (2011). The therapeutic potential of the Internet: Exploring selfhelp processes in an Internet forum for young people with inflammatory bowel disease. Gastroenterology Nursing, 34(6), 439-448. https://doi.org/10.1097/SGA.0b013e318237a9ba

Mayring, P. (2014). Qualitative content analysis: Theoretical foundation, basic procedures and software solution. Retrieved from: https://nbn-resolving.org/urn:nbn:de:0168ssoar-395173

Meng, J., Martinez, L., Holmstrom, A., Chung, M., \& Cox, J. (2017). Research on social networking sites and social support from 2004 to 2015: A narrative review and directions for future research. Cyberpsychology, Behavior, and Social Networking, 
20(1), 44-51. https://doi.org/10.1089/cyber.2016.0325

Meppelink, C. S., Smit, E. G., Fransen, M. L., \& Diviani, N. (2019). “I was right about vaccination": Confirmation bias and health literacy in online health information seeking. Journal of Health Communication, 24(2), 129-140.

https://doi.org/10.1080/10810730.2019.1583701

Modanloo, S., Stacey, D., Dunn, S., Choueiry, J., \& Harrison, D. (2019). Parent resources for early childhood vaccination: An online environmental scan. Vaccine, 37(51), 74937500. https://doi.org/10.1016/j.vaccine.2019.09.075

Mohanty, S., Leader, A. E., Gibeau, E., \& Johnson, C. (2018). Using Facebook to reach adolescents for human papillomavirus (HPV) vaccination. Vaccine, 36(40), 59555961. https://doi.org/10.1016/j.vaccine.2018.08.060

Mohd Roffeei, S. H., Abdullah, N., \& Basar, S. K. R. (2015). Seeking social support on Facebook for children with Autism Spectrum Disorders (ASDs). International Journal of Medical Informatics, 84(5), 375-385. https://doi.org/10.1016/j.ijmedinf.2015.01.015

Nan, X., \& Daily, K. (2015). Biased assimilation and need for closure: Examining the effects of mixed blogs on vaccine-related beliefs. Journal of Health Communication, 20(4), 462-471. https://doi.org/10.1080/10810730.2014.989343

National Cancer Institute (2017) Health Information National Trends Survey: HINTS FDA 2017, Cycle 2. https://hints.cancer.gov/view-questions-topics/questiondetails.aspx?PK_Cycle=9\&qid=757.

Nicholson, M. S., \& Leask, J. (2012). Lessons from an online debate about measles-mumpsrubella (MMR) immunization. Vaccine, 30(25), 3806-3812. https://doi.org/10.1016/j.vaccine.2011.10.072

Norman, C. D., \& Skinner, H. A. (2006). eHealth Literacy: Essential skills for consumer 
health in a networked world. Journal of Medical Internet Research, 8(2), e9. https://doi.org/10.2196/jmir.8.2.e9

Oh, H. J., \& Lee, B. (2012). The effect of computer-mediated social support in online communities on patient empowerment and doctor-patient communication. Health Communication, 27(1), 30-41. https://doi.org/10.1080/10410236.2011.567449

Oh, H. J., Ozkaya, E., \& LaRose, R. (2014). How does online social networking enhance life satisfaction? The relationships among online supportive interaction, affect, perceived social support, sense of community, and life satisfaction. Computers in Human Behavior, 30(1), 69-78. https://doi.org/10.1016/j.chb.2013.07.053

Ratzan, S. C., Bloom, B. R., El-Mohandes, A., Fielding, J., Gostin, L. O., Hodge, J. G., Hotez, P., Kurth, A., Larson, H. J., Nurse, J., Omer, S. B., Orenstein, W. A., Salmon, D., \& Rabin, K. (2019). The Salzburg statement on vaccination acceptance. Journal of Health Communication, 24(5), 581-583. https://doi.org/10.1080/10810730.2019.1622611

Reifegerste, D., \& Bachl, M. (2019). Informationssuche als Beziehungstat. Der Zusammenhang zwischen relationalen Faktoren und Motiven der stellvertretenden Suche nach Gesundheitsinformationen [Information seeking as an act of relationship: The association of relational variables with motives and frequency of surrogate health information seeking]. Studies in Communication and Media, 8(3), 378-412. https://doi.org/10.5771/2192-4007-2019-3-378

Roberts, M. E., Stewart, B. M., \& Tingley, D. (2019). stm: An R Package for Structural Topic Models. Journal of Statistical Software, 91(1), 1-40. https://doi.org/10.18637/jss.v091.i02

Roberts, M. E., Stewart, B. M., Tingley, D., Lucas, C., Leder-Luis, J., Gadarian, S. K., Albertson, B., \& Rand, D. G. (2014). Structural topic models for open-ended survey 
responses. American Journal of Political Science, 58(4), 1064-1082.

https://doi.org/10.1111/ajps.12103

Rosselli, R., Martini, M., \& Bragazzi, N. L. (2016). The old and the new: Vaccine hesitancy in the era of the Web 2.0. Challenges and opportunities. Journal of Preventive Medicine and Hygiene, 57(1), 47-50.

Schofield, A., \& Mimno, D. (2016). Comparing apples to apple: The effects of stemmers on topic models. Transactions of the Association for Computational Linguistics, 4, $287-$ 300. https://doi.org/10.1162/tacl_a_00099

Tanis, M. (2008). What makes the internet a place to seek social support? In E. A. Konijn, S. Utz, M. Tanis, \& S. B. Barnes (Eds.), Mediated Interpersonal Communication (pp. 290-308). New York, US: Routledge.

Tanis, M. (2012). Online social support groups. In A. N. Joinson, K. Y. A. McKenna, T. Postmes, \& U.-D. Reips (Eds.), Oxford handbook of Internet psychology (Vol. 1). Oxford: Oxford University Press. https://doi.org/10.1093/oxfordhb/9780199561803.013.0010

Teoh, D. (2019). The power of social media for HPV vaccination-Not fake news! American Society of Clinical Oncology Educational Book, 39(1), 75-78. https://doi.org/10.1200/EDBK_239363

Thoits, P. A. (2011). Mechanisms linking social ties and support to physical and mental health. Journal of Health and Social Behavior, 52(2), 145-161. https://doi.org/10.1177/0022146510395592

Thomson, A., Robinson, K., \& Vallée-Tourangeau, G. (2016). The 5As: A practical taxonomy for the determinants of vaccine uptake. Vaccine, 34(8), 1018-1024. https://doi.org/10.1016/j.vaccine.2015.11.065

van Ingen, E., Utz, S., \& Toepoel, V. (2016). Online coping after negative life events: 
Measurement, prevalence, and relation with Internet activities and well-being. Social Science Computer Review, 34(5), 511-529.

https://doi.org/10.1177/0894439315600322

World Health Organization (WHO). (2019). Substantial decline in global measles deaths, but disease still kills 90000 per year. Retrieved from: http://www.who.int/news-room/2610-2017-substantial-decline-in-global-measles-deaths-but-disease-still-kills-90-000per-year 


\section{Tables and Figures}

Table 1

Most important terms of the 27 aspects of the vaccine-related discussions

\begin{tabular}{|c|c|c|}
\hline Aspect & Perspective & Most important terms \\
\hline Booster dose & $\begin{array}{l}\text { Specific } \\
\text { vaccinations }\end{array}$ & $\begin{array}{l}\text { tetanus, pertussis/whooping cough, poliomyelitis, } \\
\text { immunity, necessary, diphtheria, years, adults }\end{array}$ \\
\hline Chickenpox & $\begin{array}{l}\text { Specific } \\
\text { vaccinations }\end{array}$ & $\begin{array}{l}\text { chickenpox, virus, illness, infected, disease, shingles, } \\
\text { protects, dangerous, fall ill, back then }\end{array}$ \\
\hline $\begin{array}{l}\text { Immunity } \\
\text { pregnancy }\end{array}$ & $\begin{array}{l}\text { Specific } \\
\text { vaccinations }\end{array}$ & $\begin{array}{l}\text { pregnancy, gynecologist, pregnant, blood, immune, } \\
\text { gestational age, during, titer, slapped cheek syndrome }\end{array}$ \\
\hline Influenza & $\begin{array}{l}\text { Specific } \\
\text { vaccinations }\end{array}$ & $\begin{array}{l}\text { flu/influenza, never, vaccinate, vaccinate against } \\
\text { influenza, flu/influenza vaccination, ill, winter, except, } \\
\text { especially, true }\end{array}$ \\
\hline $\begin{array}{l}\text { Measles and } \\
\text { mumps }\end{array}$ & $\begin{array}{l}\text { Specific } \\
\text { vaccinations }\end{array}$ & $\begin{array}{l}\text { measles, mumps, protection, vaccinated, died, } \\
\text { childhood diseases, passive immunity, protected, } \\
\text { exists, } 100\end{array}$ \\
\hline Meningococcal & $\begin{array}{l}\text { Specific } \\
\text { vaccinations }\end{array}$ & $\begin{array}{l}\text { Standing Committee on Vaccination, } \mathrm{b}, \mathrm{c}, \mathrm{a} \text {, } \\
\text { recommendation, meningococcal, recommend, } \\
\text { vaccinated, meningococcus type } \mathrm{b}\end{array}$ \\
\hline TBE & $\begin{array}{l}\text { Specific } \\
\text { vaccinations }\end{array}$ & $\begin{array}{l}\text { year, last, tick-borne encephalitis [TBE], ticks, } \\
\text { birthday, habitation, older [sibling], nursery, son }\end{array}$ \\
\hline $\begin{array}{l}\text { Vaccination } \\
\text { decision }\end{array}$ & $\begin{array}{l}\text { Specific } \\
\text { vaccinations }\end{array}$ & let, don't vaccinate, consider, against, when, uncertain \\
\hline $\begin{array}{l}\text { Compulsory } \\
\text { vaccination }\end{array}$ & $\begin{array}{l}\text { General vaccination } \\
\text { debate }\end{array}$ & $\begin{array}{l}\text { children, not vaccinated, parents, compulsory } \\
\text { vaccination, unvaccinated, die, kindergarten, fully } \\
\text { vaccinated }\end{array}$ \\
\hline $\begin{array}{l}\text { Discussion } \\
\text { tone }\end{array}$ & $\begin{array}{l}\text { General vaccination } \\
\text { debate }\end{array}$ & $\begin{array}{l}\text { opinion, please, written, discussion, wrong, why, } \\
\text { thread, topic, people }\end{array}$ \\
\hline Evidence base & $\begin{array}{l}\text { General vaccination } \\
\text { debate }\end{array}$ & $\begin{array}{l}\text { exist, vaccine injury, studies, cases, physicians, } \\
\text { connection, money, pharma industry, most, people }\end{array}$ \\
\hline $\begin{array}{l}\text { Information } \\
\text { sources }\end{array}$ & $\begin{array}{l}\text { General vaccination } \\
\text { debate }\end{array}$ & $\begin{array}{l}\text { decision, pro, decide, find, book, inform, informed, } \\
\text { make, sites, contra }\end{array}$ \\
\hline $\begin{array}{l}\text { Responsibility } \\
\text { and threats }\end{array}$ & $\begin{array}{l}\text { General vaccination } \\
\text { debate }\end{array}$ & child, live, mother, happen, protect, fear, fault, best \\
\hline $\begin{array}{l}\text { Vaccine } \\
\text { ingredients }\end{array}$ & $\begin{array}{l}\text { General vaccination } \\
\text { debate }\end{array}$ & $\begin{array}{l}\text { body, less, immune system, aluminium, antibiotics, } \\
\text { need, notably, takes effect, medicine, human }\end{array}$ \\
\hline
\end{tabular}




\begin{tabular}{|c|c|c|}
\hline Appointments & Practical issues & $\begin{array}{l}\text { week, last, next, appointment, cold, since, monday, } \\
\text { friday, days }\end{array}$ \\
\hline $\begin{array}{l}\text { Experience } \\
\text { report }\end{array}$ & Practical issues & $\begin{array}{l}\text { older [sibling], first, vaccine, both, injections, get, 6- } \\
\text { fold-vaccination, exists }\end{array}$ \\
\hline Fever & Practical issues & $\begin{array}{l}\text { fever, give, degrees, suppository, days, reaction, pain, } \\
\text { rash, vaccination reaction }\end{array}$ \\
\hline $\begin{array}{l}\text { Procedural } \\
\text { issues }\end{array}$ & Practical issues & $\begin{array}{l}\text { side effects, vaccination, vaccine, cost, health } \\
\text { insurance, pediatrician, according to, new, decided }\end{array}$ \\
\hline Tolerability & Practical issues & $\begin{array}{l}\text { first, problems, second, responded, so far, second, } \\
\text { tolerate, super, zwei }\end{array}$ \\
\hline $\begin{array}{l}\text { Vaccination } \\
\text { sequence }\end{array}$ & Practical issues & $\begin{array}{l}\text { rota, rotavirus, six-fold, pneumococcus, mmr, later, } \\
\text { early, late }\end{array}$ \\
\hline $\begin{array}{l}\text { Vaccination } \\
\text { timetable }\end{array}$ & Practical issues & 3 , months, $4,6,2,5,12$, old \\
\hline $\begin{array}{l}\text { Acknowledge } \\
\text { ments }\end{array}$ & $\begin{array}{l}\text { Relationship and } \\
\text { communication }\end{array}$ & $\begin{array}{l}\text { thank you, question, answer, respond, d, maybe, } \\
\text { thoughts, know, thought of, ask }\end{array}$ \\
\hline $\begin{array}{l}\text { Bad } \\
\text { experiences }\end{array}$ & $\begin{array}{l}\text { Relationship and } \\
\text { communication }\end{array}$ & $\begin{array}{l}\text { man/husband, really, god, happy, sorry, friend, told, } \\
\text { luck, hospital, thanks }\end{array}$ \\
\hline $\begin{array}{l}\text { Immediate } \\
\text { reactions }\end{array}$ & $\begin{array}{l}\text { Relationship and } \\
\text { communication }\end{array}$ & $\begin{array}{l}\text { mum, hurt, arm, short, went, after, scream, } \\
\text { immediately, grave, baby }\end{array}$ \\
\hline Medical advice & $\begin{array}{l}\text { Relationship and } \\
\text { communication }\end{array}$ & $\begin{array}{l}\text { doctor, pediatrician, says, ask, before, practice, regular } \\
\text { health checkup for children }\end{array}$ \\
\hline $\begin{array}{l}\text { Recovery } \\
\text { wishes }\end{array}$ & $\begin{array}{l}\text { Relationship and } \\
\text { communication }\end{array}$ & $\begin{array}{l}\text { better, soon, hope, fast, wish, oh, great, remains, } \\
\text { sounds, hopefully }\end{array}$ \\
\hline Requests & $\begin{array}{l}\text { Relationship and } \\
\text { communication }\end{array}$ & $\begin{array}{l}\text { warm greetings, hello, dear, greetings, daughter, hey, } \\
\text { experience, huhu, everyone }\end{array}$ \\
\hline
\end{tabular}

Note. The most important terms are the FREX (most frequent and exclusive) terms, i.e., the terms, which were likely to occur in posts with a topic and unlikely to occur in posts with other topics (Roberts et al., 2014). The terms were translated to English. The original German terms are documented in the supplementary materials. 


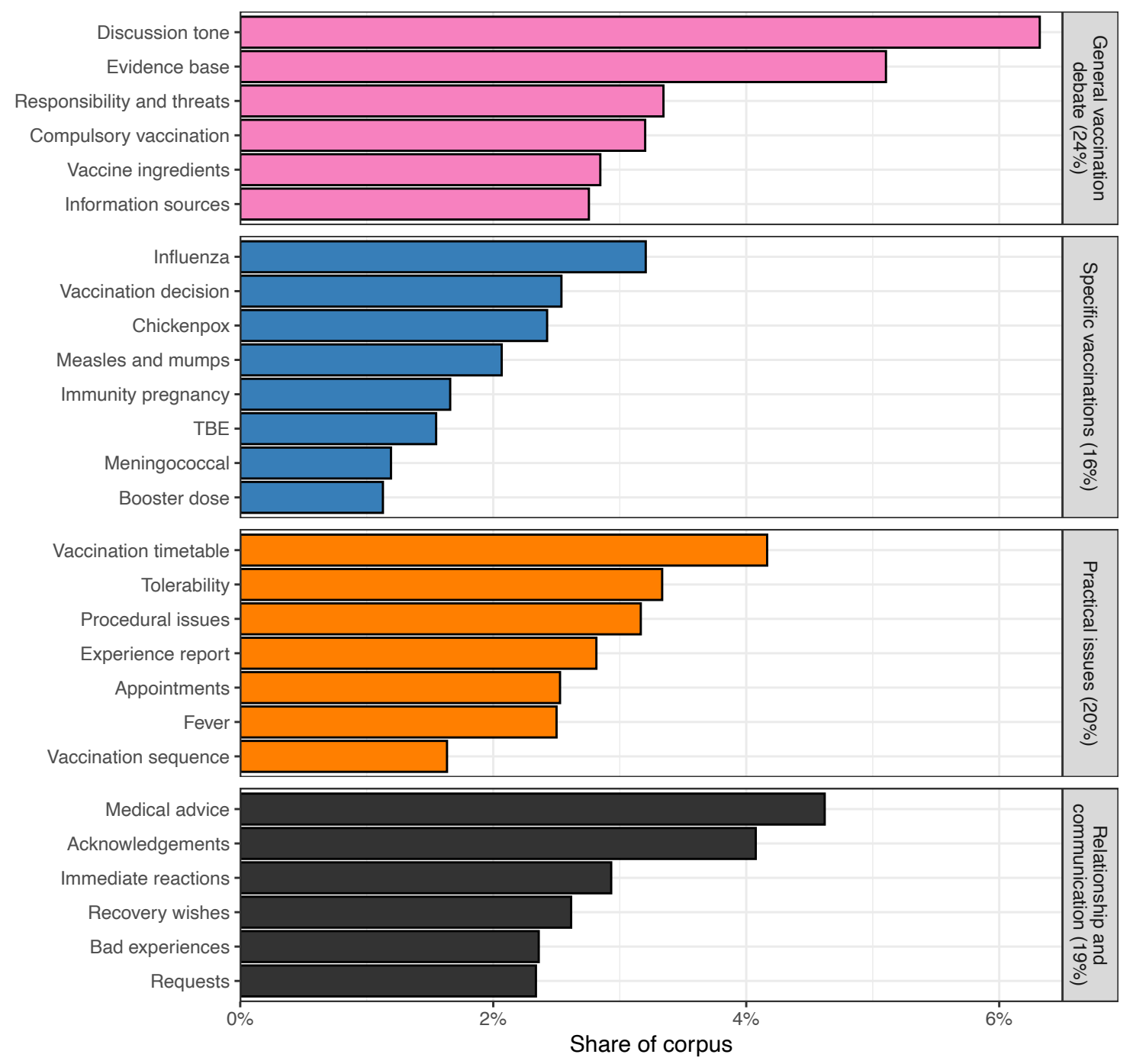

Figure 1. Prevalence of the 27 aspects of the vaccine-related discussions

Note. The figure presents the labels of the aspects on the $\mathrm{y}$ axis and their prevalence on the $\mathrm{x}$ axis. The facets show the categorization of the aspects into broader perspectives on the vaccination issue. Missing to $100 \%$ are the eight topics which were unrelated to vaccines. 
Table 2

Overview of the exchanged subtypes of social support in the four perspectives

\begin{tabular}{llll}
\hline General & Specific & Practical issues & Relationship and \\
vaccination & vaccinations & & communication \\
debate & & \\
\hline
\end{tabular}

\section{Informational}

support

\begin{tabular}{llcl}
\hline Teaching & $\mathrm{X}$ & $\mathrm{X}$ & \\
\hline Sharing own & & $\mathrm{X}$ & \\
experiences & $\mathrm{X}$ & & \\
\hline Referral to & & & \\
information & & & \\
\hline Referral to & & $\mathrm{X}$ \\
medical & & \\
expertise & & \\
\hline Practical advice & & \\
\hline
\end{tabular}

\section{Emotional}

support

\begin{tabular}{lcc}
\hline Relationships & $\mathrm{X}$ & \\
\hline Expression of & $\mathrm{X}$ & $\mathrm{X}$ \\
care, sympathy & & \\
and empathy & & \\
\hline Encouragement & $\mathrm{X}$ &
\end{tabular}

\section{Esteem support}

\begin{tabular}{lll}
\hline Validation & $\mathrm{X}$ & $\mathrm{X}$ \\
\hline
\end{tabular}

